\title{
TANDEM-X HEIGHT PERFORMANCE AND DATA COVERAGE
}

\author{
Christopher Wecklich, Carolina Gonzalez, Paola Rizzoli
}

\section{Microwaves and Radar Institute, German Aerospace Center (DLR), Christopher.Wecklich@DLR.de}

\begin{abstract}
TanDEM-X is a single-pass radar interferometric mission, which is comprised of two formation flying satellites, with the primary goal of generating a global Digital Elevation Model (DEM) of unprecedented accuracy. Between December 2010 and early 2015 all land surfaces have been acquired at least twice, difficult terrain up to seven or eight times and as of September 2016 the final TanDEM-X DEM dataset is available for download. This paper provides a final quality assessment of the TanDEM-X global DEM products with respect to the DEM relative and absolute height accuracy and data coverage both at the global and geocell level.
\end{abstract}

Index Terms - Synthetic Aperture Radar (SAR), Interferometry, Digital Elevation Model (DEM), height accuracy, data coverage, voids.

\section{INTRODUCTION}

Digital Elevation Models (DEMs) are raster-based digital datasets representing the topography of a planetary body and are of fundamental importance for a wide range of scientific and commercial applications. Within the $\pm 60^{\circ}$ latitude band, up to now data from the Shuttle Radar Topography Mission (SRTM) has been the primary source of elevation information. Since 2010 the German Aerospace Center (DLR) has been operating Germany's first two formation flying Synthetic Aperture Radar (SAR) satellites, TerraSAR-X and TanDEM-X, with the objective to generate an updated global DEM which exceeds the presently available global data sets in terms of resolution, coverage, and quality by orders of magnitude [1].

The primary mission of TanDEM-X is the generation of a world-wide, consistent, current, and high-precision DEM, with a spatial resolution of 0.4 arcseconds $(12 \mathrm{~m}$ at the equator) and according to the height accuracy and data coverage shown in Table 1. This paper presents an introduction to TanDEM-X global DEM generation and status (Section 2). This is followed by a section each dedicated to the evaluation of relative and absolute height accuracy of the available global DEM products (Sections 3.1 and 3.2, respectively). Finally the paper is concluded with an evaluation of the TanDEM-X data coverage or void density (Section 3.3).

\section{TANDEM-X GLOBAL DEM}

SAR interferometry is based on the evaluation of the phase difference between two coherent radar signals acquired from slightly different spatial and/or temporal positions. The height of the scatterer is then inferred from this range difference by geometric triangulation. As the TanDEM-X radar operates in the X-band, the resulting height represents the reflecting surface of the radar backscatter.

The mapping strategy is to cover all land masses at least twice and difficult terrain, such as mountains and deserts, at least four times for better performance [2]. When all of the input data of a larger region are processed, the tilts and offsets are calibrated out against a subset of ICESat data and differences between overlapping TanDEM-X acquisitions are harmonized. Lastly, the mosaicking processor combines all elevation data and produces almost 20,000 final DEM geocells with a size of $1^{\circ}$ by $1^{\circ}$ latitude/longitude (ca. 110 $\mathrm{km}$ by $110 \mathrm{~km}$ ) at the equator [3].

The TanDEM-X global DEM acquisition started in December 2010 and the first global coverage (except Antarctica) was completed in January 2012. By the end of 2014, the Earth's entire land mass had been mapped at least twice (four times in the case of difficult terrain) with varying baselines. Delivery of DEM products commenced in 2014 and in October 2016 delivery of all 19,389 DEM tiles covering the entire earth land mass was completed.

\section{FINAL DEM QUALITY}

This section describes the relative and absolute height accuracy as well as the data coverage of the TanDEM-X dataset.

\subsection{RELATIVE HEIGHT ACCURACY}

The DEM relative height accuracy is well described solely by system error due to random noise contributions, and can be calculated after correcting the systematic errors and

Table 1: TanDEM-X performance requirements

\begin{tabular}{|c|c|c|}
\hline Parameter & Accuracy & Requirement \\
\hline $\begin{array}{c}\text { Absolute Height } \\
\text { Accuracy }\end{array}$ & $\begin{array}{c}90 \% \text { linear error }- \\
\text { globally }\end{array}$ & $\leq 10$ meters \\
\hline $\begin{array}{c}\text { Relative Height } \\
\text { Accuracy }\end{array}$ & $\begin{array}{c}90 \% \text { linear point-to- } \\
\text { point error in } 1^{\circ} \times 1^{\circ} \\
\text { geocell }\end{array}$ & $\begin{array}{c}\leq 2 \text { meters } \\
(\text { slope } \leq 20 \%)\end{array}$ \\
\cline { 2 - 3 } & $\begin{array}{c}\leq 4 \text { meters } \\
\text { (slope }>20 \%)\end{array}$ \\
\hline Data Coverage & \multicolumn{2}{|c|}{$97 \%$ of all global land mass } \\
\hline
\end{tabular}




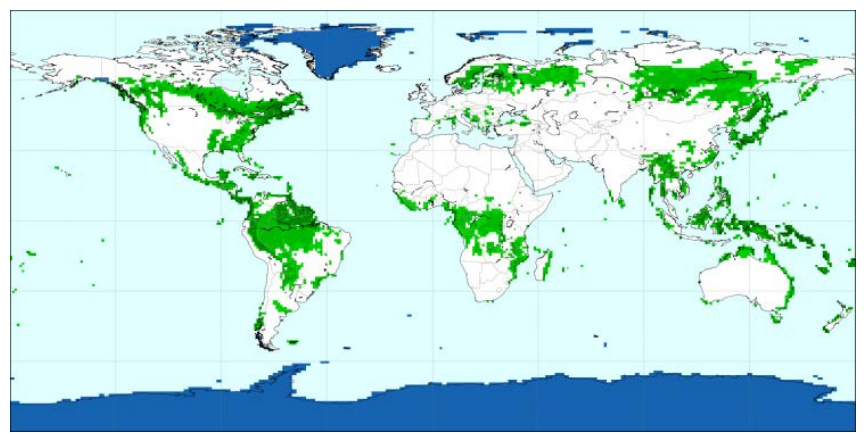

Figure 1: Forest (green) and Ice (Blue) separation for the Absolute Height Accuracy Evaluation

anomalies. For this, the TanDEM-X products contain an additional layer with pixel-wise information on the estimated relative height accuracy [4].

Of the 19,389 available TanDEM-X geocells, 16,205 have a relative height accuracy above the required $90 \%$ confidence level for the specified $2 \mathrm{~m}$ in flat $(\leq 20 \%)$ and 4 $\mathrm{m}$ in steep ( $>20 \%$ ) terrain. Of those 3,184 products that are below $90 \%, 2,095$ geocells are not considered to be reliable due to too few data points (e.g. small islands) or to ice coverage. An additional 717 geocells are dominated by highly forested areas. In these areas, the coherence estimation is artificially deteriorated due to volume decorrelation and consequently the relative height accuracy is also deteriorated [1][4]. Hence, in the entire dataset only 372 geocells, or $2.24 \%$ of the total geocells not associated with the disclaimers listed above, do not meet the relative height accuracy specification. A detailed description and evaluation of the relative height accuracy calculation, processing, and results for the final TanDEM-X DEM products can be found in [4].

\subsection{ABSOLUTE HEIGHT ACCURACY}

The absolute height accuracy of the TanDEM-X data has been globally validated using the ICESat points that have not already been utilized in the calibration process to evaluate the difference between ICESat and TanDEM-X data [3]. When evaluating the absolute height accuracy on a global scale, only the first 1,000 points with the lowest height variation between DEM pixels within an ICESat footprint are considered. Hence, geocells with fewer validation points (e.g. coastal regions) are evaluated with similar weight as geocells with more copious validation points.

When evaluating the absolute height accuracy, all tiles are separated into the following categories using the GLOBCOVER 2010 classification map [5] and PALSAR forest/non-forest map [6]; Forest, where the forest coverage is greater than $60 \%$, Ice, where the ice coverage is greater than $60 \%$ and includes all of Antarctica, and Generic, which do not contain forest nor ice tiles. This separation is shown in Figure 1.

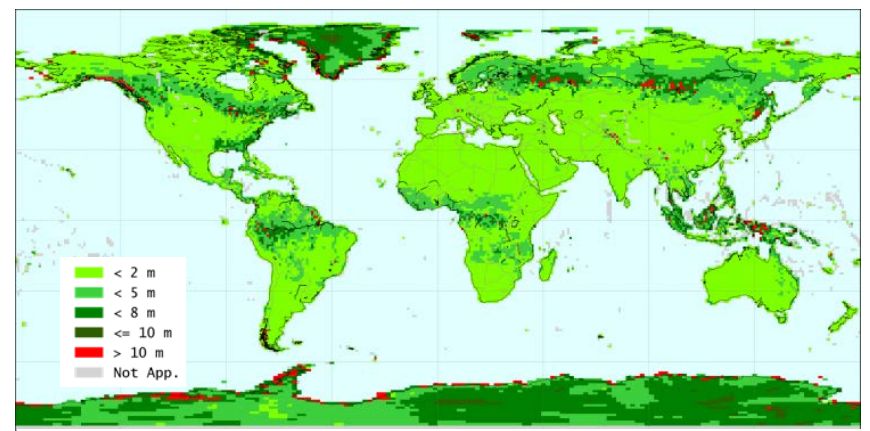

Figure 2: Absolute Height Accuracy results on a tile-by-tile basis

Figure 2 shows the TanDEM-X absolute height accuracy on a tile-by-tile basis. Starting with the generic case where ice and forest tiles are excluded and which contains approximately 10 million validation points, the absolute height accuracy with a $90 \%$ linear error is an impressive 0.877 meters and a mean height deviation of only 0.045 meters. Next looking at the forest only case, the evaluation of the validation points shows a mean height deviation of 0.5687 meters and an absolute height accuracy with $90 \%$ Linear Error of 2.330 meters. As this height difference is TanDEM-X height minus IceSAT height, the positive mean height difference of 0.5687 meters over forested land where the laser based system of IceSAT penetrates the forest canopy more than the radar based TanDEM-X system is expected. Now turning to the case of ice tiles only, in Greenland and Antarctica the difference in terms of penetration depth is so large that a dedicated calibration process had to be considered, in which DEM calibration using ICESat data was only performed on the rocky edges of the land mass and then extended into the middle by applying a self-adjusting block calibration process. Thus one sees, as expected, that the absolute height accuracy over ice regions significantly increases to 6.372 meters and that the mean absolute height error drops down to -2.83 meters with some geocells going below -5 meters. Figure 3 shows the mean height difference and one clearly sees the signal penetration offset between the laser-based ICESat data and the radar-based TanDEM-X height technology over Greenland and Antarctica (negative) as well as the various forest regions (positive). It should be mentioned that the final three rows

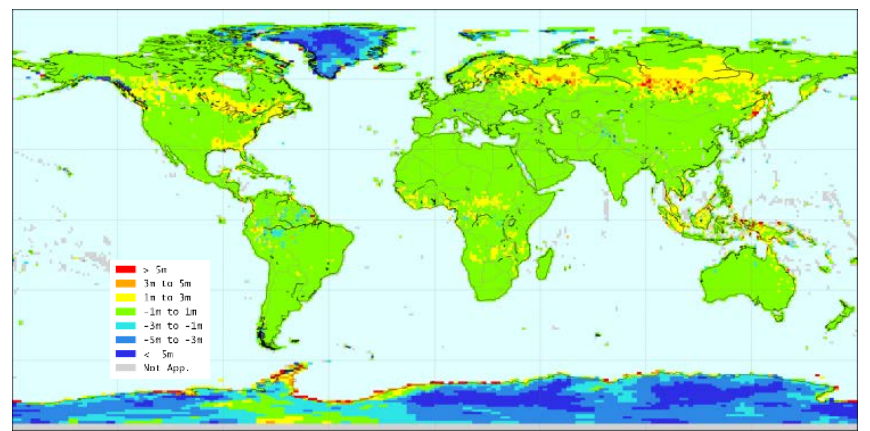

Figure 3: Mean height difference of the TanDEM-X dataset 


\begin{tabular}{|l|c|c|c|c|}
\hline \multicolumn{1}{|c|}{ Statistics } & $\begin{array}{c}\text { Generic } \\
\text { Tiles }\end{array}$ & $\begin{array}{c}\text { Ice } \\
\text { Only }\end{array}$ & $\begin{array}{c}\text { Forest } \\
\text { Only }\end{array}$ & All Tiles \\
\hline $\begin{array}{l}\text { Number of DEM } \\
\text { Tiles }\end{array}$ & 12,257 & 3,019 & 4,113 & 19,389 \\
\hline Landmass (sqkm) & $97 \mathrm{mi}$. & $14 \mathrm{mi}$. & $33 \mathrm{mi}$. & $144 \mathrm{mi}$. \\
\hline $\begin{array}{l}\text { Number of Val. } \\
\text { Points }\end{array}$ & $10 \mathrm{mi}$. & $2 \mathrm{mi}$. & $3 \mathrm{mi}$. & $15 \mathrm{mi}$. \\
\hline $\begin{array}{l}\text { Mean Height } \\
\text { Deviation of Val. } \\
\text { Points (m) }\end{array}$ & 0.0448 & -2.8329 & 0.5687 & -0.3707 \\
\hline $\begin{array}{l}\text { Absolute Height } \\
\text { Accuracy of } 10 \mathrm{~m} \\
\text { linear error) }\end{array}$ & $99.84 \%$ & $98.42 \%$ & $99.17 \%$ & $99.48 \%$ \\
\hline $\begin{array}{l}\text { Absolute Height } \\
\text { Accuracy with } 90 \% \\
\text { Linear Error (m) }\end{array}$ & $\mathbf{0 . 8 7 7}$ & $\mathbf{6 . 3 7 2}$ & $\mathbf{2 . 3 3}$ & $\mathbf{3 . 4 9 4}$ \\
\hline
\end{tabular}

Table 2: Summary of final Absolute Height Accuracy for various scenarios

of DEM tiles, namely latitudes from -90 to -88 degrees, over Antarctica have no ICESat data points for validation as the ICESat system did not cover this region. Finally coming to the complete global performance, which includes both ice and forest lands, the system specification of an absolute global height accuracy of at most 10 meters with a $90 \%$ linear error is met and far exceeded with an overall accuracy of 3.494 meters.

The final absolute height statistics of the TanDEM-X DEMs for the different scenarios are summarized in Table 2 and Figure 4 shows each scenario's histograms. The histograms from the different division of land show a near symmetry for the case of generic land, the negative height effects due to different system technology in the case of ice tiles, a noticeable increase in positive height in the case of forest land, and the significant negative height contribution from the ice tiles in the case of all global tiles. Returning to Figure 2, out of 19,389 analyzed geocells, only 328 tiles or $1.69 \%$ have an absolute height accuracy greater than $10 \mathrm{~m}$. The vast majority of the geocells, over 10,954 or $56 \%$, have an absolute height accuracy of less than $2 \mathrm{~m}$.

\subsection{Data Coverage}

Voids, i.e. invalid pixels, in DEM data arise when a pixel's height value cannot be determined during processing and can occur in a SAR system for various reasons, including phase unwrapping anomalies, low return signal power, or shadow/layover effects. The TanDEM-X final DEM is specified to the data coverage requirement shown in Table 1 and therefore the global data set can have up to $3 \%$ invalid data points (voids) over land (VOL).

The TanDEM-X DEM void pixels over land and water pixels are both flagged with the same invalid flag. In order to separate the voids over land from voids over water, a land/water body mask is needed. Between $56^{\circ}$ south and $60^{\circ}$ north latitudes the 30 meter resolution SRTM Water Body
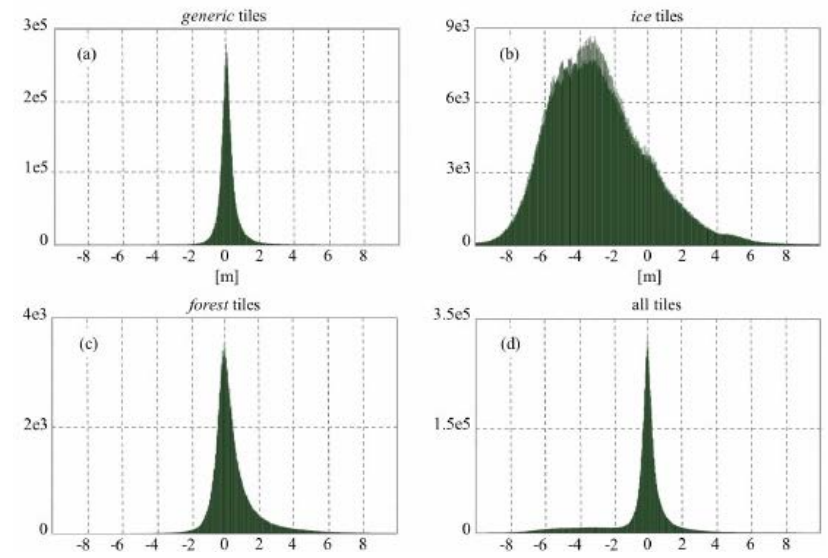

Figure 4: Histograms of the absolute height accuracy for generic tiles (a), ice tiles (b), forest tiles (c), and all tiles (d).

Data (SWBD) is utilized for the majority of the geocells [7]. The SWBD does not contain data for a few geocells in the desert regions and small islands, thus a second land mask is needed in these areas. For the remainder of the globe, including Antarctica, and for the missing areas in the SWBD, the European Space Agency's (ESA) Climate Change Initiative Land Cover (CCI - LC) data set is utilized [8]. The CCI-LC mask represents open and permanent water bodies at a $300 \mathrm{~m}$ spatial resolution on a global scale.

Of the total 19,389 geocells in the TanDEM-X dataset, voids over land account for only $0.107 \%$ of the entire data set. In other words the data coverage is currently better than $99.89 \%$. Figure 5 shows the status of the global data coverage on a geocell level after removing tiles with land less than $1 \%$. Over $67 \%$ of the geocells shown in this figure contain zero invalid data pixels. Furthermore, only 1,366 or $7.0 \%$ of the geocells contain more than 1 percent of invalid pixels over land.

Figure 6 shows an example geocell of the data coverage for both the unedited SRTM Version 1.0 and TanDEM X data in the Sahara desert centered at North $23.5^{\circ}$ East $13.5^{\circ}$ where black represents invalid data. In this example, the original SRTM data has a coverage of less than $75 \%$ whereas the TanDEM-X has full $(100 \%)$ data coverage. This difference in void amount demonstrates the highly improved completeness of the TanDEM-X data, which is

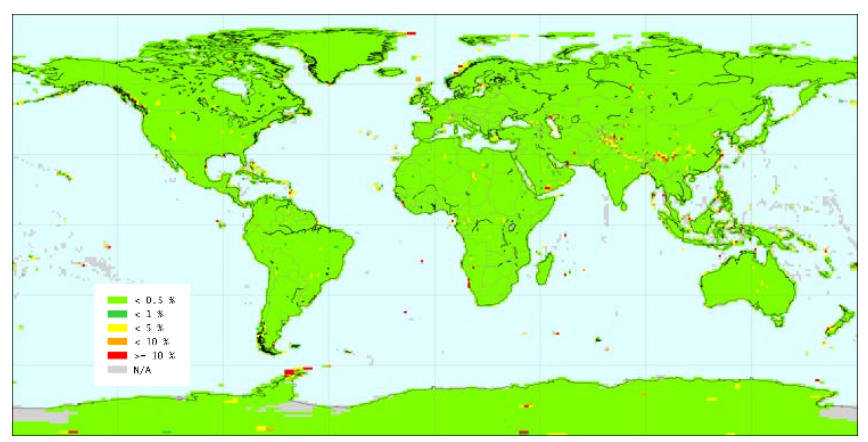

Figure 5: Data Coverage of the TanDEM-X Dataset 

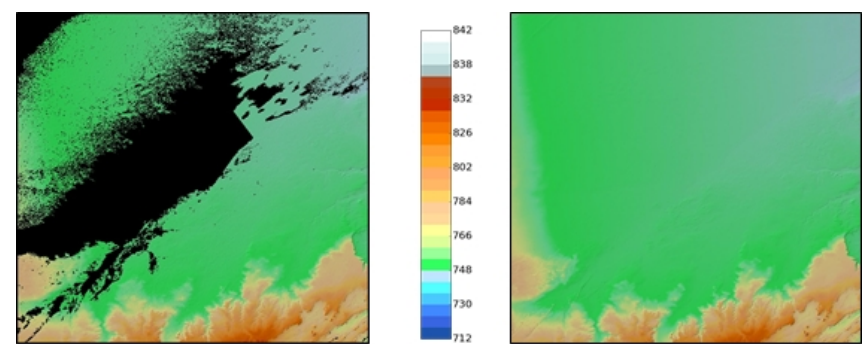

Figure 6: SRTM unedited version 1.0 (left) and TanDEM-X (right) DEMs at North $23.5^{\circ}$ East $13.5^{\circ}$ where black represents invalid data. In this case, the SRTM data contains over $25 \%$ voids whereas the TanDEM-X data contains none.

especially visible in the desert areas of the Sahara and the Middle East, where TanDEM-X performed at least two additional coverages with a steep viewing angle for an improved backscatter return [9].

\section{CONCLUSION}

The TanDEM-X mission is an innovative system for space borne radar remote sensing, enabling the systematic acquisition of a global, highly accurate DEM with unprecedented resolution and accuracy. The first geocells of the global TanDEM-X DEM became available in 2014 and as of October 2016, all 19,389 geocells are available covering the entire Earth's land mass.

The relative height accuracy of the final DEM from TanDEM-X is specified to meet a linear point-to-point accuracy of $2 \mathrm{~m}(4 \mathrm{~m})$ with a $90 \%$ confidence level for flat (steep) terrain within a geocell. It has been shown in this paper that 19,017 out of the available 19,389 geocells or $97.8 \%$ fulfill the relative height accuracy specification.

The final DEM product shall demonstrate an absolute height accuracy of no more than 10 meter with a $90 \%$ linear error. For areas excluding ice and forest, the final DEM reaches a level of absolute height accuracy better than one meter and when all the validation points are included, the requirement is met and far exceeded with an absolute height accuracy of 3.494 meters using approximately 15 million validation points.

And finally, the TanDEM-X data set is specified with a global data coverage of at least $97 \%$ over land. It has been shown that the TanDEM-X DEM data currently exceeds this with an extremely low void percentage of $0.107 \%$ of the global geocells which corresponds to a data coverage of 99.9\% and well above the mission requirement.

In conclusion, the results presented in this paper for the performance of the TanDEM-X DEM data demonstrate the exceptional quality of this global Digital Elevation Model.

\section{REFERENCES}

[1] G. Krieger, A. Moreira, H. Fiedler, I. Hajnsek, M. Werner, M. Younis, M. Zink, "TanDEM-X: A Satellite
Formation for High Resolution SAR Interferometry," IEEE Transactions on Geoscience and Remote Sensing, vol. 45, no. 11, pp. 3317-3341, 2007.

[2] D. B. Tridon, M. Bachmann, D. Schulze, C. OrtegaMìguez, M. D. Polimeni, M. Martone, J. Böer, and M. Zink, "TanDEM-X: DEM acquisition in the third year era," Int. J. of Space Science and Engineering, vol. 1, no. 4, pp 367-381, 2013.

[3] B. Wessel, A. Gruber, A. Wendleder, M. Huber, M. Breunig, U. Marschalk, D. Kosmann, A. Roth, "Production Chain towards First Calibrated and Mosaicked TanDEM-X DEMs", IGARSS pp 2432-2435, Vancouver, Canada, 2011.

[4] C. Gonzalez and B. Bräutigam, "Relative Height Accuracy Analysis of TanDEM-X DEM Products", European Conference on Synthetic Aperture Radar, Hamburg, Germany, 2016.

[5] European space agency GlobCover portal, Jan. 2015.

[6] M. Shimada, T. Itoh, T. Motooka, M. Watanabe, T. Shiraishi, R. Thapa, and R. Lucas, "New global forest/non-forest maps from ALOS PALSAR data (2007-2010)," Remote Sensing of Environment, vol. 155, pp. 13-31, May 2014.

[7] NASA Shuttle Radar Topography Mission Water Body Data Shapefiles \& Raster Files https://lpdaac.usgs.gov/dataset_discovery/measures/me asures_products_table/srtmswbd (Visited on 11/13/2015).

[8] European Space Agency Climate Change Initiative Global Water Bodies - http://www.esa-landcovercci.org/?q=node/162 (Visited on 11/13/2015).

[9] M. Martone, P. Rizzoli, B. Bräutigam, and G. Krieger, "First two years of TanDEM-X mission: interferometric performance overview," Radio Science, vol. 48, pp. 617-627, October 2013. 